\title{
Fabricating a versatile cement-retained implant provisional restoration with a customized temporary abutment
}

\begin{abstract}
The utilization of an implant-supported provisional restoration is essential to the development of an anatomical gingival architecture, which is needed to attain an esthetically pleasing final restoration. Both screw-retained and cement-retained provisional restorations can be utilized for immediate or delayed provisionalization, each with their benefits and shortcomings. This article describes a versatile technique for fabricating a cement-retained implant provisional restoration that allows for extra-oral customization of the provisional abutment to provide the desired emergence profile, and allows for the cement margin to be visible for precise removal of excess cement.
\end{abstract}

Keywords: easy cement removal, customized emergence profile, esthetic temporary crown
Volume 6 Issue 6 - 2017

\author{
Wook Jin Seong,' Hardeep S Birdi, ${ }^{2}$ James \\ Hinrichs $^{3}$ \\ 'Department of Restorative Sciences, University of Minnesota, \\ USA \\ 2Private Practice, Vancouver, Canada \\ ${ }^{3}$ Department of Developmental and Surgical Sciences, University \\ of Minnesota, USA
}

\begin{abstract}
Correspondence: Wook Jin Seong, Associate Professor and Director, Division of Prosthodontics, Department of Restorative Sciences, School of Dentistry, University of Minnesota, 515 Delaware St. SE, Minneapolis, MN 55II 3 USA, Tel 6I2-625-5677, Email seong00I@umn.edu
\end{abstract}

Received: January 16, 2017 | Published: April 03, 2017

\section{Introduction}

The fabrication of an implant-supported provisional restoration is an important step in achieving an esthetic and functional final restoration. ${ }^{1,2}$ Numerous different techniques have been reported in the literature with their respective benefits and limitations. ${ }^{3-8}$ However, all techniques do agree that an implant provisional restoration is needed to develop and maintain the gingival architecture, and to finally provide the necessary information needed in order to fabricate the highest quality definitive restoration possible. Both screw-retained and cement-retained provisional restorations can be utilized for immediate or delayed provisionalization. ${ }^{9}$ Complications associated with screw-retained provisional restorations include proliferation of granulation tissue as a consequence of screw loosening, plaque accumulation, and even abutment screw fracture. ${ }^{10}$ This could result in a compromised final esthetic outcome. The other main concern with screw-retained provisional restorations occurs in the maxillary anterior area where the screw access hole is often seen penetrating through the facial surface of the provisional crown, resulting in challenging, and time-consuming esthetic filling of the access hole. ${ }^{11}$ Conversely, cement-retained provisional restorations have the main concern of retaining excess cement after cementation. ${ }^{12}$ This could lead to complications such as inflammation, bleeding, excess bone loss, and even implant loss. ${ }^{13,14}$ Numerous techniques have been advocated to prevent the accumulation of excess cement. ${ }^{15-18}$ However, many of these techniques are difficult to implement for immediate temporization, especially in immediate implant placement situations. Lemongello ${ }^{5}$ has previously demonstrated a method of customizing a provisional abutment and restoration for an immediately placed implant. However, their technique involved customization of the provisional abutment intra-orally the day after implant placement. This case report describes a technique for immediately fabricating a cement-retained implant provisional restoration that allows for extraoral customization of the provisional abutment to provide the desired emergence profile and allows for the cement margin to be visible for precise removal of excess cement.

\section{Case presentation}

A 24-year old female was referred from a private orthodontic practice for a replacement of a maxillary left central incisor suffering from a severe external root resorption (Figure 1). Even though the maxillary right central incisor and left lateral incisor also had significant root resorptions, the patient wanted to delay those treatments and address only an extremely mobile maxillary left central incisor for financial reasons. Prior to an implant placement surgery, diagnostic models and tooth shade were obtained. Utilizing polyvinyl siloxane putty material, a provisional restoration matrix was fabricated before the surgery. A maxillary left central incisor was extracted and an endosseous dental implant was immediately placed at the extraction site without opening a flap (Figure 2). After a prefabricated temporary abutment was fully seated on top of the implant, the desired reduction of incisal height and cingulum area was marked with a permanent marker. The temporary abutment was removed and prepared extra-orally with a bur to ensure a proper relief. The proper reduction of temporary abutment was verified intra-orally via provisional restoration matrix. A $1.5 \times 1.5 \mathrm{~cm}$ piece of rubber dam was cut out, a small hole was punched in the center of the dam, and 
placed around the trimmed temporary abutment intro-orally to cover proximal papillae and cervical undercuts of adjacent teeth (Figure 3). The rubber dam was lowered cervically to cover the apical one-third of the trimmed abutment in order to prevent provisional restoration material from flowing into the undercuts and the surgical site. A cotton pallet was placed into the temporary abutment screw hole to prevent provisional restoration material from flowing into the screw access hole. As a separating medium, a petroleum jelly was applied to the incisal two-thirds of the trimmed temporary abutment above the rubber dam. The provisional restoration material was injected into the putty matrix and the matrix was inserted over the adjacent teeth and temporary abutment with rubber dam in place (Figure 4). After the provisional restoration material set, the temporary crown (incisal two-thirds of ideal tooth contour) and the piece of rubber dam were carefully removed (Figure 5). The excess provisional restoration material was trimmed extra-orally in order to fabricate the ideal contour of the provisional crown and create a flat butt-joint margin at the junction between the incisal two-thirds of the crown and cervical one-third as a to-be-customized temporary abutment. This step was important to prevent the provisional crown from locking to the future customized temporary abutment. Petroleum jelly was applied to the flat butt-joint margin and slightly up onto the axial walls of the provisional crown. A lubricated flat butt-joint margin was critical to prevent the flowable composite material used to create the cervical portion of the customized abutment from bonding to the provisional crown. The ideal location of cement margin between the crown and the customized abutment was slightly supra-gingival or at the height of the gingival margin to enhance removal of excess temporary cement. The trimmed prefabricated temporary abutment with rubber dam was removed from the patient's mouth (Figure 6) and re-connected to the implant analog. The ideally contoured and lubricated provisional crown (incisal two-thirds of ideal tooth contour) was positioned back onto the temporary abutment/implant analogue and a complete seating was confirmed. A 3-dimensional space between the flat butt-joint margin of the provisional crown and the prefabricated temporary abutment margin was filled with flowable composite and light cured (Figure 7). The effort was applied to ensure a desired emergence profile had been developed. After the light-cured excess flowable composite over the axial walls of provisional crown was trimmed away, the provisional crown was lifted carefully from the now-customized temporary abutment (Figure 8). The customized temporary abutment was re-connected onto the implant intra-orally and the abutment screw was hand-tightened (Figure 9). The proximal contacts, occlusion, smile line, and both labial and lingual contours of the provisional crown were adjusted and the screw of the customized temporary abutment was tightened with a torque wrench. The abutment screw access hole was sealed with cotton and the provisional crown was cemented using temporary cement over the customized temporary abutment (Figure 10). Any excess cement was now easily removed since the margins were at or above the free gingival margin. Furthermore, the provisional crown may be refabricated or further revised without removing the customized temporary abutment, thereby ensuring the undisturbed healing and development of the desired gingival contours. At 2 weeks from the surgery, customized temporary abutment labial margin was lowered and a new provisional crown was fabricated to achieve a better esthetic. Radiograph showed the location of temporary abutment margin and a reasonably ideal emergence profile of a customized temporary abutment made of flowable composite (Figure 11). In two months, the final all ceramic restoration was cemented on custom $\mathrm{CAD} / \mathrm{CAM}$ zirconia abutment The emergence profiles of both flowable composite customized temporary abutment and zirconia custom CAD/CAM abutment look quite similar each other (Figure 12).

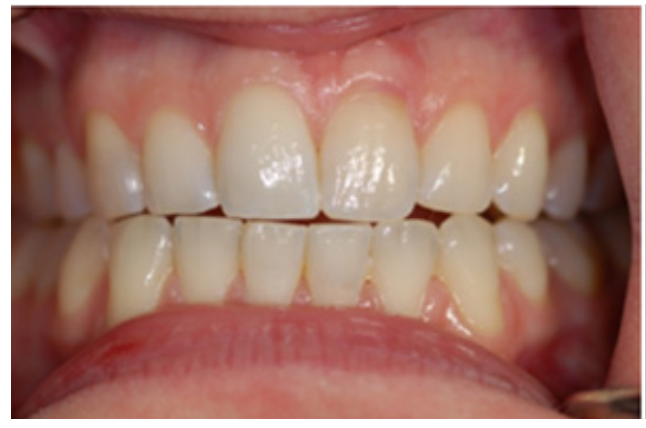

Figure I Pre-treatment view. Maxillary left central incisor was planned to be replaced with a dental implant restoration due to the post-orthodontic external root resorption complication.

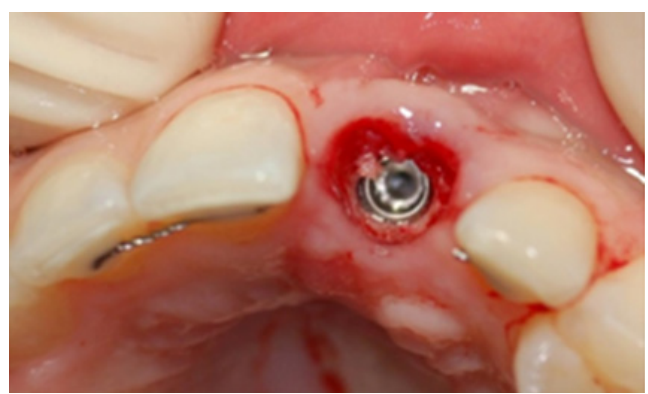

Figure 2 Implant was placed in maxillary left central incisor position immediately after extraction without a flap.

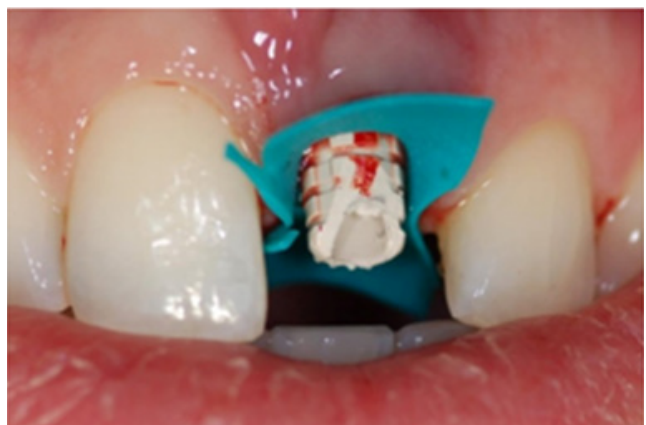

Figure $3 \mathrm{~A}$ piece of rubber dam is placed around the trimmed temporary abutment to protect the surgical site and block out proximal undercuts.

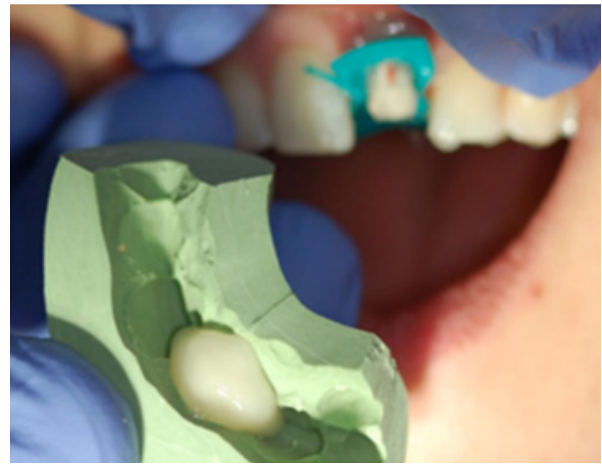

Figure 4 While rubber dam is in place, provisional restoration material was applied to the separating medium covered trimmed temporary abutment using a putty matrix. 

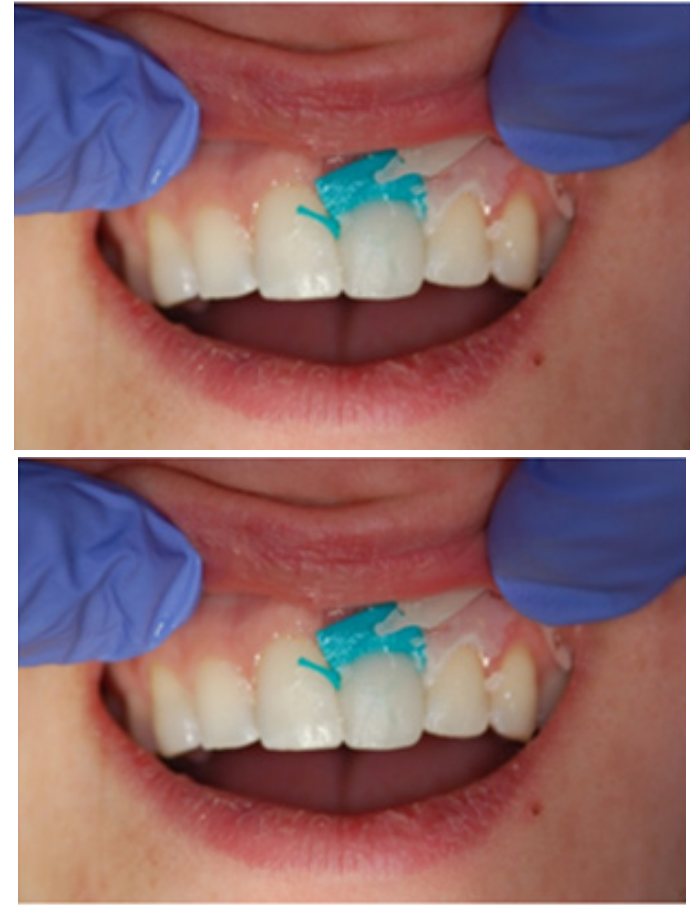

Figure 5A \& 5B A:A self-cured provisional crown was set; $B$ : A provisional crown was removed from the temporary abutment and block-out cotton was coming out with it.

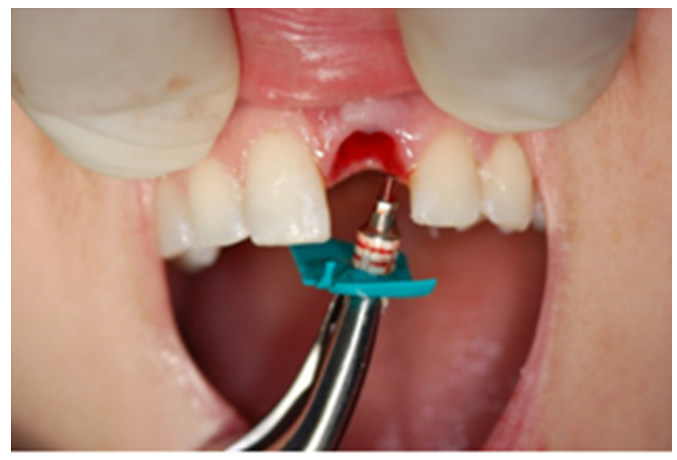

Figure 6 The trimmed prefabricated temporary abutment with rubber dam was removed from the patient's mouth.

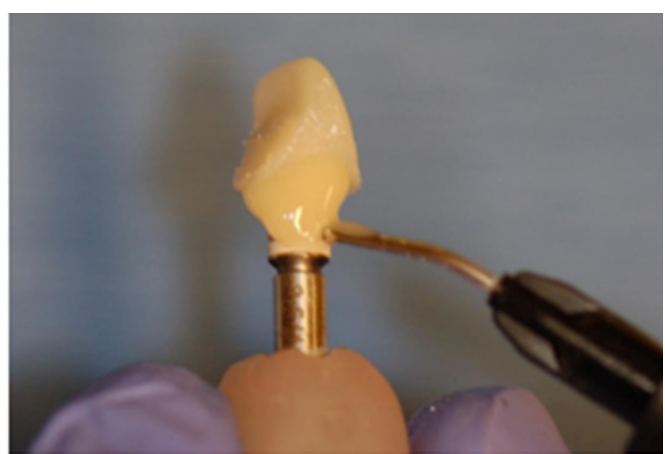

Figure 7 The 3-dimensional space between provisional crown fabricated intraorally with rubber dam and the preformed margin of temporary abutment is filled with flowable composite while achieving an ideal emergence profile. Separating medium is only applied on temporary crown side, not to the abutment margin side so that flowable composite can bond to the temporary abutment.

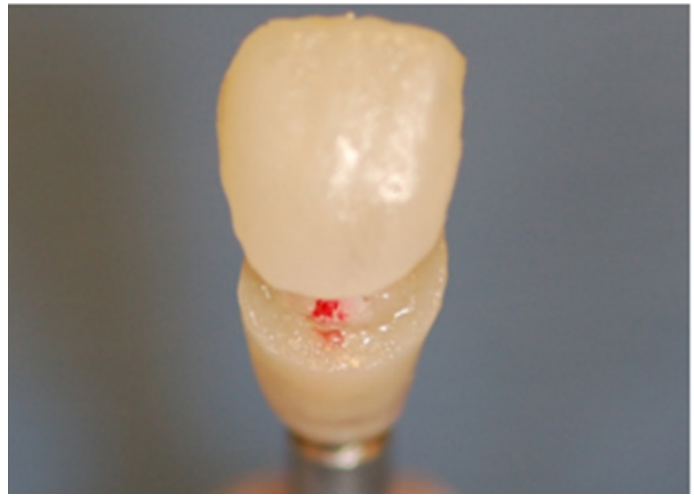

Figure 8 A provisional crown is lifted carefully from the customized temporary abutment.

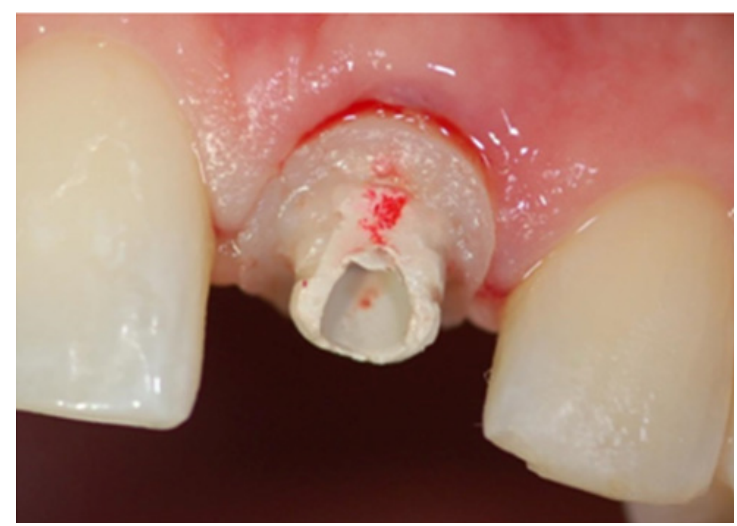

Figure 9 Customized temporary abutment was placed back onto the implant and the abutment screw was hand-tightened.
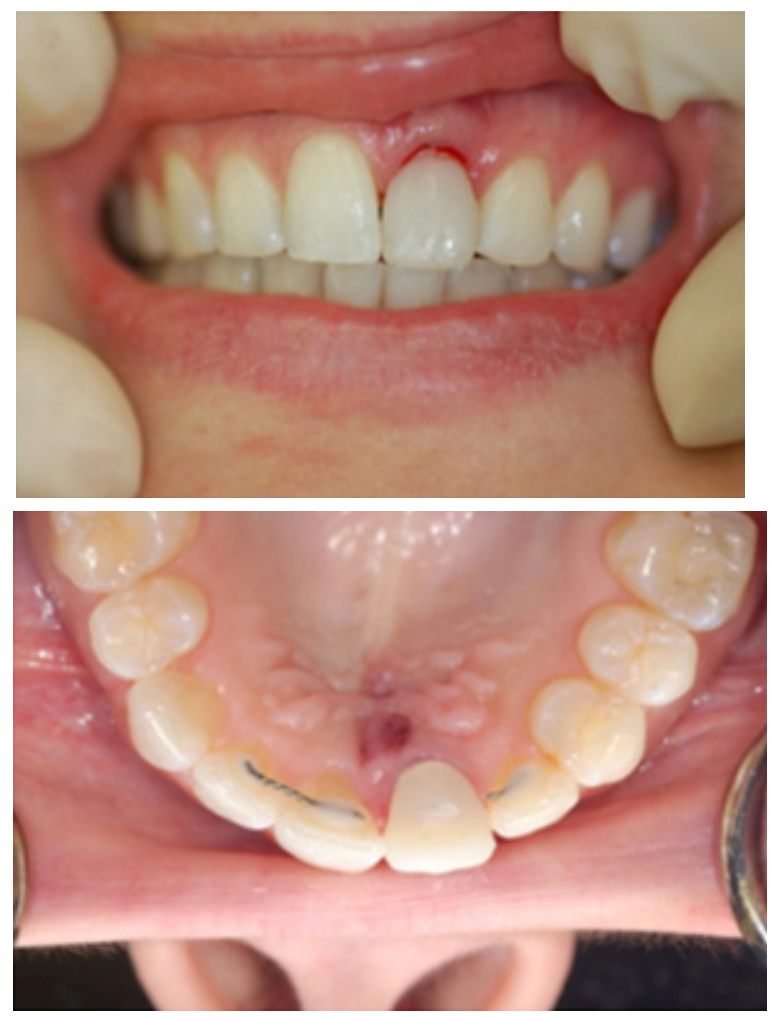

Citation: Seong WJ, Birdi HS, Hinrichs J. Fabricating a versatile cement-retained implant provisional restoration with a customized temporary abutment. J Dent Health Oral Disord Ther. 2017;6(6): I77-I8I. DOI: 10.15406/jdhodt.2017.06.00220 


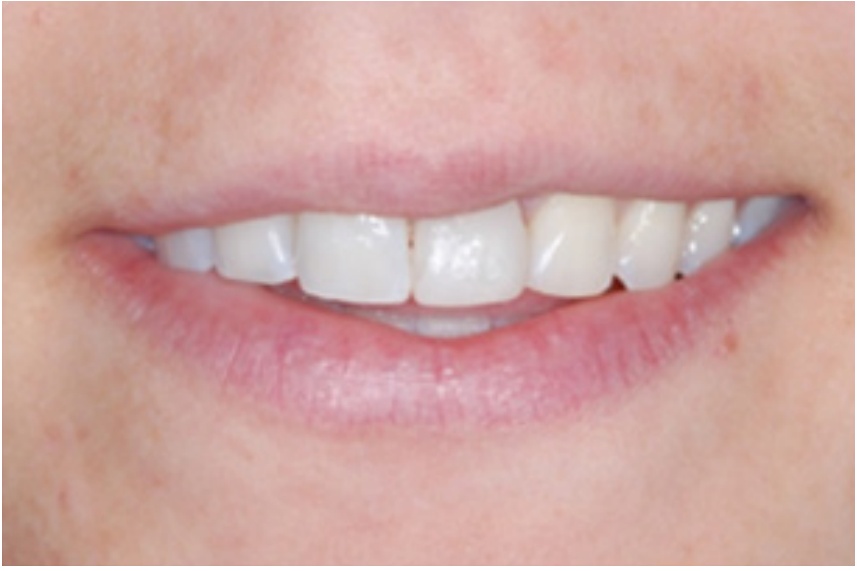

Figure I0A,B \& C (A) Provisional crown was cemented with temporary cement after abutment screw access hole was covered with cotton. Complete removal of excess cement was easily achieved. (B\&C) Labial and lingual contours, and smile looked harmonious.
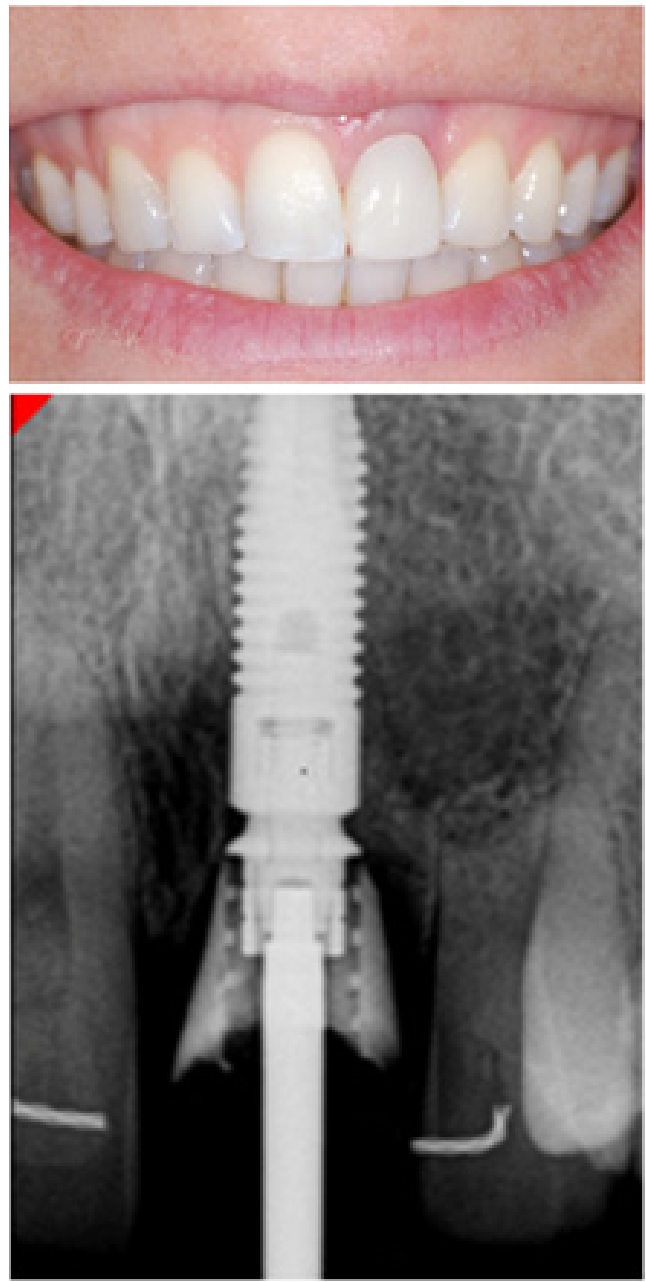

Figure I I (A) At 2 weeks from surgery, the customized temporary abutment labial margin was lowered and a new maxillary left central incisor provisional crown was fabricated for a better esthetic; (B) Radiograph showed a provisional crown-temporary abutment margin and an ideal emergence profile of customized temporary abutment made of flowable composite.
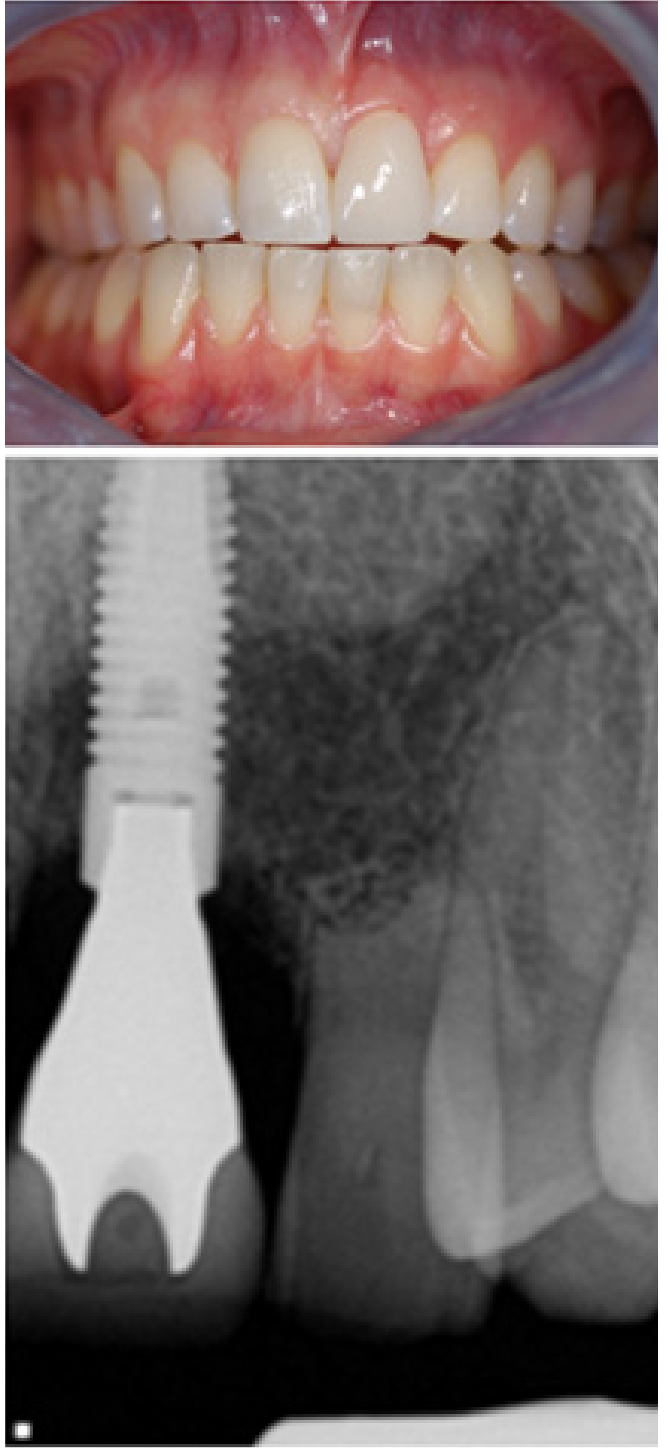

Figure 12 (A) Final restoration was cemented on zirconia CAD/CAM custom abutment; (B) Radiograph showed about the same emergence profile of zirconia abutment compared to one of customized temporary abutment.

\section{Discussion}

This is a very versatile technique which can predictably produce esthetic results (no need for a labial composite to seal a temporary abutment screw hole) with an equi-gingival cement margin (low chance for cement-induced complications) while promoting ideal soft tissue contours by customizing temporary abutment contours. It also can be used virtually in any situation; at first stage or second stage surgery appointments with or without flap opening, no matter whether implant angulation is tilted labially or lingually, and no matter how deep or shallow an implant is placed into the bone. Both screw-retained and cement-retained implant provisional restorations have their limitations. This universal technique can virtually eliminate incomplete cement removal problems while maintaining all the advantages of cement-retained provisional restorations thereby providing an esthetic and functional provisional restoration. Furthermore, this technique can be utilized at first stage or second stage surgeries, and in immediate implant placement situations. 


\section{Acknowledgments}

None.

\section{Conflicts of interest}

The authors declare there are no conflicts of interest.

\section{References}

1. Higginbottom F, Belser U, Jones JD, et al. Prosthetic management of implants in the esthetic zone. Int J Oral Maxillofac Implants. 2004;19 Suppl:62-72.

2. Buser D, Martin W, Belser UC. Optimizing esthetics for implant restorations in the anterior maxilla: Anatomic and surgical considerations. Int J Oral Maxillofac Implants. 2004;19 Suppl:43-61.

3. Del Castillo RA. Immediate provisionalization of a single-tooth implant with a temporary cylinder in one surgical appointment. Pract Proced Aesthet Dent. 2006;18(5) Suppl:3-5.

4. Ganddini MR, Tallents RH, Ercoli C, et al. Technique for fabricating a cement-retained single-unit implant-supported provisional restoration in the esthetic zone. J Prosthet Dent. 2005;94(3):296-298.

5. Lemongello GJ. Customized provisional abutment and provisional restoration for an immediately-placed implant. Pract Proced Aesthet Dent. 2007;19(7):419-424.

6. Lemongello GJ. Immediate custom implant provisionalization: A prosthetic technique. Pract Proced Aesthet Dent. 2007;19(5):273-279.

7. Shor A, Schuler R, Goto Y. Indirect implant-supported fixed provisional restoration in the esthetic zone: Fabrication technique and treatment workflow. J Esthet Restor Dent. 2008;20(2):82-95.

8. Vafiadis D, Goldstein G, Garber D, et al. Immediate Implant Placement of a Single Central Incisor Using a CAD/CAM Crown-Root Form Technique: Provisional to Final Restoration. J Esthet Restor Dent. 2017;29(1):13-21.
9. Lee A, Okayasu K, Wang HL. Screw- versus cement-retained implant restorations: Current concepts. Implant Dent. 2010;19(1):8-15.

10. Theoharidou A, Petridis HP, Tzannas K, et al. Abutment screw loosening in single-implant restorations: A systematic review. Int J Oral Maxillofac Implants. 2008;23(4):681-690.

11. Al Harbi SA, Edgin WA. Preservation of soft tissue contours with immediate screw-retained provisional implant crown. J Prosthet Dent. 2007;98(4):329-332.

12. Pauletto N, Lahiffe BJ, Walton JN. Complications associated with excess cement around crowns on osseointegrated implants: A clinical report. Int J Oral Maxillofac Implants. 1999;14(6):865-858.

13. Thomas GW. The positive relationship between excess cement and periimplant disease: A prospective clinical endoscopic study. J Periodontol. 2009;80(9):1388-1392.

14. Gapski R, Neugeboren N, Pomeranz AZ, et al. Endosseous implant failure influenced by crown cementation: A clinical case report. Int J Oral Maxillofac Implants. 2008;23(5):943-946

15. Agar JR, Cameron SM, Hughbanks JC, et al. Cement removal from restorations luted to titanium abutments with simulated subgingival margins. J Prosthet Dent. 1997;78(1):43-47.

16. Dumbrigue HB, Abanomi AA, Cheng LL. Techniques to minimize excess luting agent in cement-retained implant restorations. J Prosthet Dent. 2002;87(1):112-114.

17. Schwedhelm ER, Lepe X, Aw TC. A crown venting technique for the cementation of implant-supported crowns. J Prosthet Dent. 2003;89(1):89-90.

18. Santosa RE, Martin W, Morton D. Effects of a cementing technique in addition to luting agent on the uniaxial retention force of a single-tooth implant-supported restoration: An in vitro study. Int J Oral Maxillofac Implants. 2010;25(6):1145-1152. 